\title{
Characterization of Root-Knot Nematode Populations Associated with Vegetables in New York State
}

\author{
N. A. Mitkowski, Department of Plant Pathology, Cornell University, Geneva, NY 14456; J. G. Van der Beek, \\ Research Institute of Plant Protection (IPO-DLO), Wageningen, Netherlands; and G. S. Abawi, Department of Plant \\ Pathology, Cornell University, Geneva, NY 14456
}

\begin{abstract}
Mitkowski, N. A., Van der Beek, J. G., and Abawi, G. S. 2002. Characterization of root-knot nematode populations associated with vegetables in New York State. Plant Dis. 86:840-847.

The northern root-knot nematode (Meloidogyne hapla) causes significant damage on vegetables in New York State. This study was conducted to determine if other species of Meloidogyne are also present in New York vegetable fields and to better characterize the root-knot populations in order to facilitate the development of effective rotations for nematode management. Populations of Meloidogyne were collected from 18 vegetable fields across New York and maintained in the greenhouse on tomato cv. Rutgers as both field populations and single-female populations. For the purposes of species identification, nematodes from each population were examined using perineal pattern analysis, scanning electron microscopy, and cytological analysis. All techniques identified the presence of only Meloidogyne hapla in the collected samples. The host range of the populations of Meloidogyne that were collected was investigated using a modified form of the North Carolina Differential Host Test. While host ranges were variable among the collected populations, the host range of all populations closely corresponded to that of M. hapla. The internal transcribed spacer region (ITS1) of the collected populations was amplified and sequenced. All sequences from the collected populations corresponded to the published sequence of M. hapla. Based on these results, it was concluded that M. hapla is the only root-knot nematode species present in New York vegetable fields. Crop rotational strategies for management of the root-knot nematode on vegetables in New York should be devised to reflect this fact.
\end{abstract}

Vegetable production is a major agricultural industry in New York State. Several vegetable crops including potatoes, onions, carrots, snap beans, sweet corn, and lettuce are grown on both organic and mineral soils. Many of these commodities are grown for the fresh market and generate a high return. In 2000, 17.2 million hundredweight of vegetables were grown for the fresh market in New York, for a total value of $\$ 335$ million (18). As a result of the esthetic requirements of these crops, disease organisms such as root-knot nematodes (Meloidogyne spp.) can have severe negative economic impacts. Carrots and other root crops that are infected by this nematode typically undergo severe root forking and galling $(21,28)$. Overall plant size is reduced, and severely infected plants are predisposed to environmental stresses and may be more susceptible to infection by other pathogens. In many cases, the harvested crops are unmarketable. Onions infected by the nematode typically produce significantly smaller bulbs than uninfected plants because of

Corresponding author: N. A. Mitkowski

E-mail: mitkowski@uri.edu

Accepted for publication 18 March 2002.

Publication no. D-2002-0528-03R

(C) 2002 The American Phytopathological Society reduced ability of infected roots to absorb nutrients and water. Delayed maturity of onions can also occur as a result of nematode infection and can cause difficulties in harvesting in short growing season regions such as New York $(1,28)$.

Chemical nematicides have traditionally been the primary management option employed against root-knot nematodes $(2,15)$. These chemicals are extremely toxic, and there has been considerable concern over their safety and environmental impact. Additionally, the regular use of nematicides increases production costs. Consequently, there has been an increased interest in using alternative and integrated approaches to control nematode diseases. Before these approaches can be successfully employed, however, it is necessary to understand the diversity and population biology of the pathogens present within a specific area.

It has generally been assumed that the northern root-knot nematode (Meloidogyne hapla Chitwood) is the only species of root-knot nematode that exists in commercial vegetable production fields in the northeastern United States. While the other three most common root-knot nematode species (M. incognita (Kofoid \& White) Chitwood, $M$. javanica Chitwood, and $M$. arenaria Chitwood) are capable of causing significant damage on a wide variety of vegetable crops, these species are considered tropical to subtropical organisms and are unable to survive the freezing temperatures commonly encountered during the winter months in the northeastern United States (26). In addition to M. hapla, Meloidogyne chitwoodi Golden, O'Bannon, Santo \& Finley is also capable of surviving freezing temperatures and of parasitizing vegetable crops (26). M. chitwoodi has
Table 1. Origin and host of populations of Meloidogyne collected from New York State vegetable fields

\begin{tabular}{lcccc}
\hline Population $^{\mathbf{a}}$ & $\begin{array}{c}\text { Date of } \\
\text { collection }\end{array}$ & County & $\begin{array}{c}\text { Crop in cultivation } \\
\text { (at collection) }\end{array}$ & Soil type \\
\hline MH97-1 & $7-22-97$ & Yates & Carrot & Organic \\
MH97-2 & $7-22-97$ & Wayne & Carrot & Organic \\
MH97-3 & $7-30-97$ & Cayuga & Celery & Organic \\
MH97-4 & $7-30-97$ & Cayuga & Onion & Organic \\
MH97-5 & $7-30-97$ & Oswego & Onion & Organic \\
MH97-6 & $7-30-97$ & Oswego & Onion & Organic \\
MH97-7 & $7-30-97$ & Cayuga & Onion & Mineral \\
MH97-8 & $7-30-97$ & Oswego & Onion & Organic \\
MH97-9 & $8-5-97$ & Wayne & Carrot & Organic \\
MH97-10 & $8-19-97$ & Schuyler & Lettuce & Mineral \\
MH97-11 & $9-17-97$ & Orleans & Carrot & Mineral \\
MH97-12 & $6-1-94$ & Orleans & Carrot & Mineral \\
MH97-13 & $6-1-94$ & Orleans & Carrot & Mineral \\
MH97-14 & $6-2-98$ & Genesee & Onion & Mineral \\
MH97-15 & $6-2-98$ & Genesee & Onion & Organic \\
MH97-16 & $6-2-98$ & Genesee & Onion & Organic \\
MH97-17 & $6-2-98$ & Genesee & Onion & Organic \\
MH97-18 & $5-27-98$ & Orange & Onion & Organic \\
\hline
\end{tabular}

${ }^{a}$ MH97-12 and MH97-13 were collected in 1994 and maintained in the greenhouse on tomato until 1997, when they were replanted with new seedlings. MH97-12 was a bulked collection of single female populations from MH97-13, and MH97-13 was an original field population. 
been reported from across the northwestern United States and east to Virginia (27). It infects onion, carrot, potato, sugar beet, tomato, alfalfa, corn, wheat, and a number of other important crops $(10,19)$. Because of its ability to infect a number of economically important crops grown in New York, its ability to thrive in temperate climates, and its presence in Virginia, it is important that its presence in vegetable fields within New York be determined.

This study was conducted to identify the species of root-knot nematodes present in vegetable crops in New York using morphological, cytological, and molecular methods.

\section{MATERIALS AND METHODS}

Collection and maintenance of rootknot nematode populations. Sixteen populations of Meloidogyne were collected from vegetable crops in eight counties in New York State during the summers of
1997 and 1998 (Table 1). In addition, two populations that were collected in 1994 and maintained in the greenhouse were included in this study. Each population was obtained from a single production field. Five composite soil samples, each consisting of approximately 10 subsamples, were collected from each field. The soil samples from each field were bulked and thoroughly mixed, and approximately 1.5 liters of soil from each field was placed in a 20$\mathrm{cm}$ pot and planted with tomato (Lycopersicon esculentum Mill.) cv. Rutgers. The remaining soil from each field was put into cold storage (at approximately $4^{\circ} \mathrm{C}$ ) in case it was needed for additional studies. To avoid contamination, wire mesh was placed on the surface of the corrugated greenhouse bench, and the planted pots were placed in deep nursery pots $(45 \mathrm{~cm}$ diameter) separated by at least $40 \mathrm{~cm}$ on the bench. Plants were allowed to grow for at least 3 months in the greenhouse (at approximately $25^{\circ} \mathrm{C}$ ) before nematodes were extracted for analysis.

Ten single-female cultures were then derived from each of the collected field populations, except MH97-12, MH97-15, MH97-16, and MH97-17, which were examined as field populations. Singlefemale cultures were generated by excising an infected root and removing a single egg mass from a mature female using fine forceps under a dissecting microscope. The egg mass was then placed into a 5-mmdiameter hole, $3 \mathrm{~cm}$ below the soil line in a 20 -cm pot containing a 3 -week-old tomato seedling. Contamination was prevented by placing a 10-cm-high collar (made from 20 -cm-diameter pieces of plastic drainage pipe) on top of the pots. Nematodes were extracted for analysis after 3 months.

Perineal pattern morphology. Four to 10 females from each single-female popu-
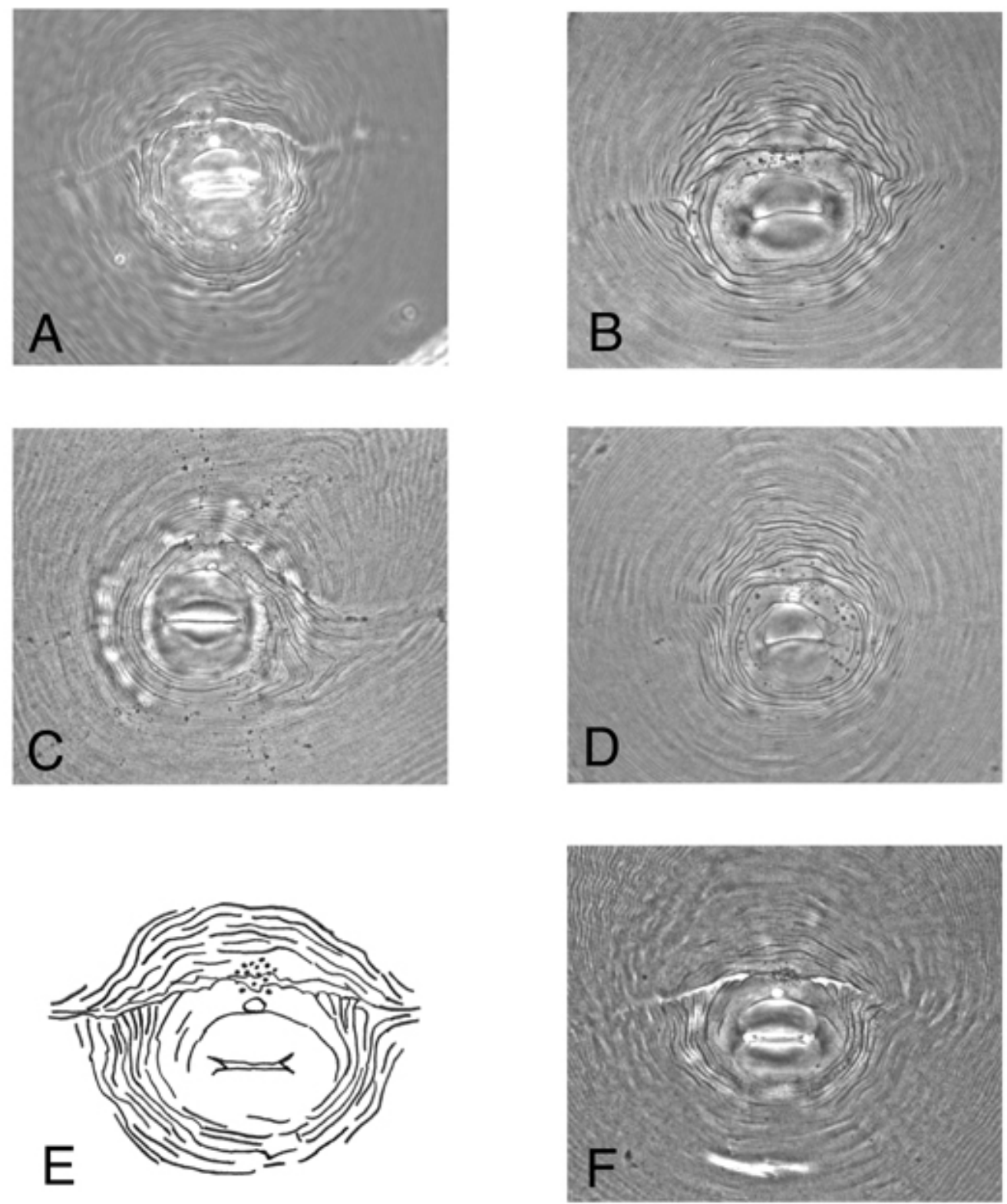

Fig. 1. Perineal patterns of selected New York populations. A, MH97-2, B, MH97-3, C, MH97-6 with observable lateral "wing”, D, MH97-13, E, Outline sketch of MH97-7, F, MH97-7. 
lation were analyzed by perineal pattern morphology. Because of a shortage of greenhouse space, single-female populations were not derived from the field populations of MH97-12, MH97-15, MH97-16, and MH97-17, and 20 to 30 perineal patterns were observed from each of these populations. Approximately 800 perineal patterns were examined. Perineal patterns were prepared as described in the literature $(12,23)$ and examined under a compound microscope at $\times 500$ and $\times 640$ and photographed using Kodak TMAX 100 film.

Scanning electron microscopy. The head region of juveniles and males from the established root-knot nematode populations were examined under the scanning electron microscope. Eisenback demonstrated that the anterior lip region of the four most common Meloidogyne species can be used for identification (8). Nematodes to be used for scanning electron microscopy were extracted from approximately $500 \mathrm{ml}$ of infested soil using a semiautomated elutriator (3). Nematodes were collected on a no. 500 sieve nested underneath a no. 60 sieve. A minimum of 1,000 juveniles and males were collected and placed in a container that consisted of a two-piece, threaded white plastic tube originally designed to store stir-bars. The tubes were cut to $1 \mathrm{~cm}$ in length, and a 1cm-diameter no. 500 mesh metal screen was attached to the open ends, resulting in a closable container through which liquids could easily pass. The container with the nematodes was then placed in $3 \%$ glutaraldehyde for $24 \mathrm{~h}$, and then transferred to a solution of $1 \%$ osmium tetraoxide for at least $24 \mathrm{~h}$. The nematodes then underwent a serial alcohol dehydration by placing the container in succession into $10,20,40,60$, 70, 90, and $100 \%$ ethanol each for $1 \mathrm{~h}$. After an additional hour in $100 \%$ ethanol, the container with the nematodes was placed into a Belzer Union CPD 020 Critical Point Dryer, where critical point drying of the nematodes was accomplished utilizing carbon dioxide. After critical point drying, the container was opened and placed directly on conductive tape attached to an SEM mounting stub, and the nematodes were transferred to the stub and firmly affixed by the tape. The stub was then placed in a Belzer Union SCD 040 Sputter Coater and coated for 1 min with gold-palladium. Nematodes were visualized on a Hitachi S-530 Scanning Electron Microscope at $10 \mathrm{kV}$ and photographed with Type 55 Polaroid film.

Cytological analysis. Seven of the populations of M. hapla (MH97-2, MH97-3, MH97-8, MH97-11, MH97-13, MH97-14, and MH97-18) were cytologically examined to identify their race-type and ploidy level. Eight egg-mass producing females from each population were dissected from the roots and examined. Preparation of slides, fixation, staining with Hoechst 33258, and observations were done according to Van der Beek et al. (25). The slides were examined with $\times 1,000$ magnification under a Zeiss Axioplan UV microscope with excitation filter G265, beam splitter FT395, and barrier filter LP420.
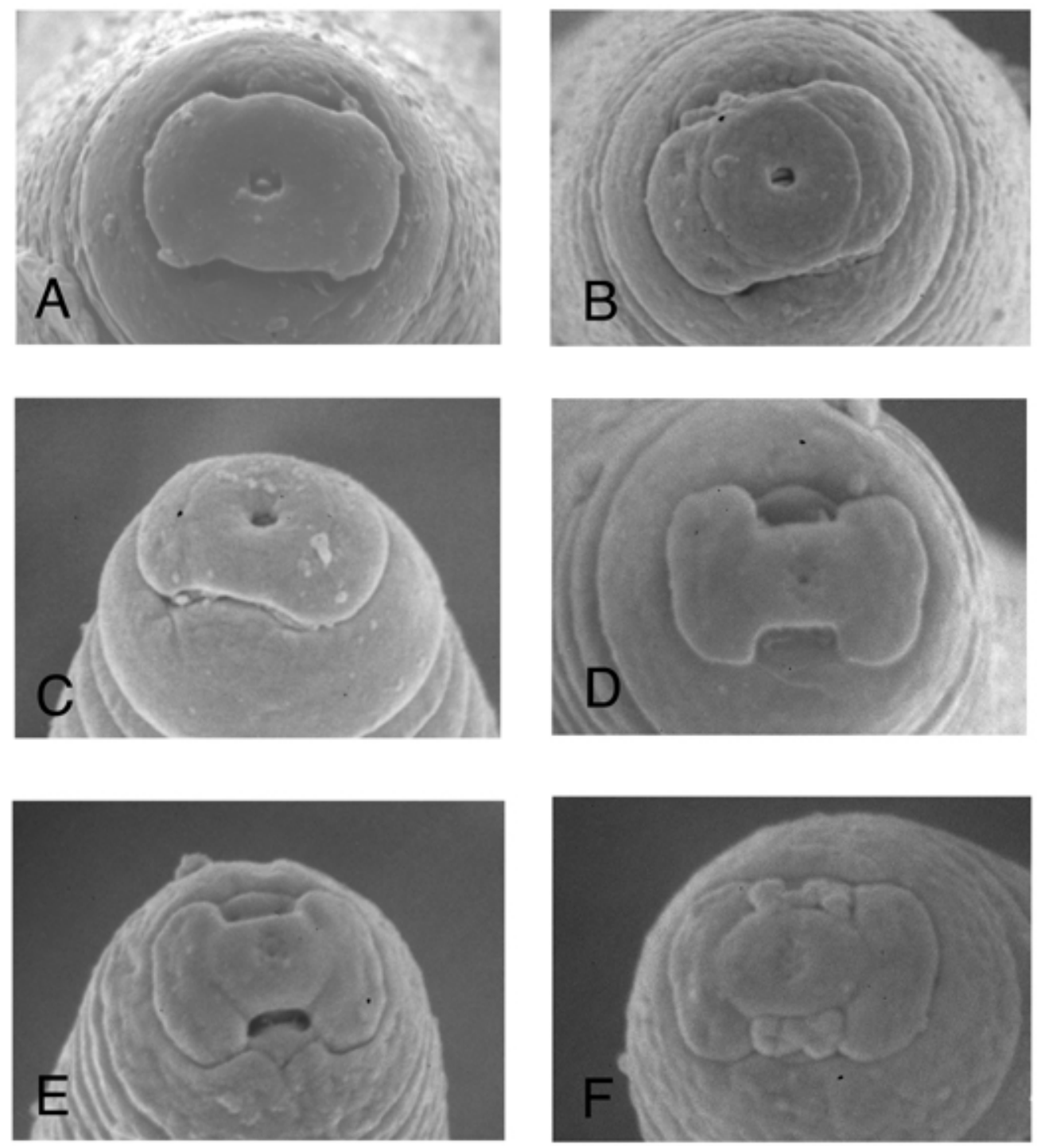

Fig. 2. Scanning electron micrographs of the lip region of males (A to C) and juveniles (D to F) from selected New York populations. A, MH97-7, B, MH97-11, C, MH97-11, D, MH97-11, E, MH97-9, F, MH97-6. 
North Carolina Differential Host Test. All populations for which perineal patterns were examined, except for MH97-3, were tested using the North Carolina Differential Host Test (NCDHT). Population MH97-17 was also included in these tests, although no perineal patterns were examined for this population. In addition to tomato cv. Rutgers, pepper cv. California Wonder (Capsicum annuum L.), tobacco cv. NC95 (Nicotiana tabacum L.), watermelon cv. Charleston Grey (Citrullus lanatus (Thunb.) Mansf.), peanut cv. Florunner (Arachis hypogaea L.) and cotton cv. DP61 (Gossypium hirsutum L.), which are commonly included in the NCDHT (20), wheat cv. Nugaines (Triticum aestivum L.) was included as a host to detect $M$. chitwoodi. Four individual plants of each differential host species were tested for each population. Plants were inoculated when they were approximately $10 \mathrm{~cm}$ tall using 5,000 eggs of the appropriate population per plant. Inoculum for each population was extracted from tomato using $1 \%$ sodium hypochlorite and delivered in $3 \mathrm{ml}$ of water to a $0.5-\mathrm{cm}$-diameter hole that was $3 \mathrm{~cm}$ from the stem of each plant.

After 8 weeks, plants were removed from pots and the roots were washed clean of soil. Nematode eggs were extracted by shaking the roots vigorously in $1 \%$ sodium hypochlorite in an Erlenmeyer flask for 3.5 min (14). The flask contents were emptied onto a no. 100 sieve nested on top of a no. 500 sieve and washed for $5 \mathrm{~min}$ and counted under a dissecting microscope. Soil from pots containing a subset of populations was processed using a semiautomatic elutriator to determine the number of juveniles that were present. A reproductive factor (Rf), defined as the number of eggs and juveniles extracted divided by 5,000 (the number used to inoculate the pot), was calculated for each population on each differential. The differential hosts were classified as nonhost ( $\mathrm{Rf}=0)$, poor host $(\mathrm{Rf}<1)$, maintenance host $(\mathrm{Rf} \geq 1$ and $\leq 3)$, good host (>3 and $\leq 10$ ), or excellent host $(>10)(10)$.

Internal transcribed spacer (ITS) region. Because perineal pattern analysis indicated that only $M$. hapla was present, primers were identified which were optimized for $M$. hapla ITS1 amplification (17). The ITS1 region was amplified and sequenced from all Meloidogyne populations collected except MH97-4, MH97-12, MH97-15, and MH97-16. The ITS1 from a single population of $M$. arenaria was also amplified and sequenced. Primers rDNA2 (5'-TTGATTACGTCCCTGCCCTTT-3') and rDNA1.58s (5'-ACGAGCCGAGTG ATCCACCG-3') were synthesized by Sigma Genosys, Inc., The Woodlands, TX. Twelve or more nematodes were utilized in this study to generate one sequence (with three nematodes used per reaction tube). Nematodes for ITS1 amplification were obtained through sodium hypochlorite extraction of eggs from egg masses collected from tomato as described above. Extracted eggs were incubated in tap water for at least 1 week in a $250-\mathrm{ml}$ beaker at $20^{\circ} \mathrm{C}$, hatched into second-stage juveniles, and transferred to a large glass counting dish. Three nematodes were then removed from the counting dish using a fine steel probe and placed in a 6- $\mu$ l drop of sterile distilled water. The nematodes were then crushed in the water using the steel probe and pipetted into a $0.6 \mathrm{ml}$ microcentrifuge tube (16). Four tubes were prepared per sequence. Each reaction tube consisted of a total of $14 \mu \mathrm{l}$ of sterile distilled water, three crushed nematodes, and polymerase chain reaction (PCR) reactants supplied by Promega Corp. (Madison, WI) that included: $2.5 \mu \mathrm{l}$ of $25 \mathrm{mM} \mathrm{MgCl} 2,2.5 \mu \mathrm{l}$ of magnesium free buffer, $1.3 \mu \mathrm{l}$ of $200 \mu \mathrm{M}$ dNTPs, and $0.5 \mu \mathrm{l}$ each of $10 \mu \mathrm{M}$ primer. Light mineral oil was then added to each tube to cover the reaction mixture. Tubes were placed into an MJ PTC-100 thermal cycler (Waltham, MA) at $94^{\circ} \mathrm{C}$, and 0.5 unit of Taq DNA polymerase (Promega
Corp.) was then added to each tube, through the mineral oil. The program for the cycler was as follows: $1 \mathrm{~min}$ at $94^{\circ} \mathrm{C}, 1$ min at $59^{\circ} \mathrm{C}$, and $2 \mathrm{~min}$ at $72^{\circ} \mathrm{C}$ repeated 25 times, followed by $5 \mathrm{~min}$ of extension at $72^{\circ} \mathrm{C}$. After amplification, reaction products were run on a $1 \%$ agarose gel, and the amplified DNA was extracted using a Qiagen Gel Extraction kit and an IEC microcentrifuge. Purified DNA from the four combined reactions was quantified against an $\phi X 174$ DNA/HaeIII restricted plasmid standard and sequenced at the Cornell Bioresource Center (Ithaca, NY) using an ABI 3700 Automated Sequencer. Sequences from these populations were aligned using the ClustalW method of the MEGAlign component application of Lasergene (DNAstar, Madison, WI) and compared with the M. hapla published sequence of this region (17; GenBank Accession U96303).

\section{RESULTS}

Perineal pattern analysis. Most perineal patterns were typical of $M$. hapla, as described in the literature (Fig. 1). The majority of patterns lacked wings or broad lateral patterns extending away from the vulva, but a number of nematodes examined from several populations did exhibit this morphology (Fig. 1C).

Scanning electron microscopy. Scanning electron microscope examination of the male lip regions of the examined populations were diagnostic for M. hapla (Fig. 2 ) and were similar to those reported in the literature $(8,11)$. The labial disk of the male nematodes was raised slightly above the medial disk. The medial lips were crescent shaped with a slight indentation at the point of fusion with the labial disk. Lateral lips were not observed in males from population MH97-7, but were identified in males from all the other populations. The head region was set off distinctly from body annules in all populations, and cephalic sensilla were not observed. Inner

Table 2. Reproductive factor of the populations of Meloidogyne from vegetable fields in New York on the North Carolina Differential Host Test

\begin{tabular}{|c|c|c|c|c|c|c|c|}
\hline \multirow[b]{2}{*}{ Population } & \multicolumn{7}{|c|}{ Reproductive factor $^{\mathbf{a}}$} \\
\hline & Tobacco & Watermelon & Pepper & Tomato & Peanut & Cotton & Wheat \\
\hline MH97-1 & 36 & - & 27 & 18 & 6 & - & - \\
\hline MH97-2 & 30 & 1 & 25 & 179 & 25 & - & - \\
\hline МH97-4 & - & - & 13 & 9 & 0.5 & - & - \\
\hline MH97-5 & 25 & - & 20 & 75 & 1 & - & - \\
\hline MH97-6 & 11 & - & 12 & 97 & 13 & - & - \\
\hline MH97-7 & - & - & 51 & 209 & 5 & - & - \\
\hline MH97-8 & 5 & - & 5 & 7 & 5 & - & - \\
\hline MH97-9 & 5 & - & 48 & 168 & 4 & - & - \\
\hline MH97-10 & 35 & 1 & 32 & 220 & 20 & - & - \\
\hline MH97-11 & 6 & - & 30 & 60 & 4 & - & - \\
\hline MH97-13 & 15 & - & 29 & 149 & 16 & - & - \\
\hline MH97-14 & 18 & - & 17 & 117 & 2 & - & - \\
\hline MH97-17 & 14 & - & 16 & 145 & 8 & - & - \\
\hline MH97-18 & 38 & - & 22 & 97 & 32 & - & - \\
\hline
\end{tabular}

${ }^{a}$ Reproductive Factor $(\mathrm{Pf} / \mathrm{Pi})$, where $\mathrm{Pf}$ is the number of eggs + juveniles recovered from soil 8 weeks after inoculation and Pi is initial inoculation level. The plant species were classified as a nonhost $(\mathrm{Rf}=0)$, poor host $(\mathrm{Rf}<1)$, maintenance host $(\mathrm{RF} \geq 1$ and $\leq 3)$, good host $(\mathrm{RF}>3 \leq 10)$, or an excellent host (RF > 10). Wheat was included to distinguish Meloidogyne chitwoodi. 
labial sensilla opened out into the prestoma in most individuals.

Juvenile lip regions are less distinct between species and thus have less diagnostic value, but all populations examined were consistent with $M$. hapla. Lateral lips were not observed in the MH97-6 population, but all other populations possessed lateral lips (Fig. 2). The labial disk was slightly raised in all populations, the head region was distinctly set off from the body annules, and the six inner labial sensilla were present in a hexagonal formation around the prestoma. Medial lips observed from all populations had a typical dumbbell shape and rounded outer edges.

Cytological analysis. Cytological observations demonstrated that populations
MH97-2, MH97-3, MH97-11, MH97-13, MH97-14, and MH97-18 all belong to cytological race $A$. The race-type of MH97-8 could not be identified with certainty because unclear metaphase I configurations were seen during meiosis but pairing of homologous chromosomes was not observed. All populations were diploid, and the chromosome numbers of three populations could be determined with reasonable certainty: MH978 with $\mathrm{n}=15$, MH97-11 with $\mathrm{n}=17$, and MH97-13 with $\mathrm{n}=15$. In MH97-11, some females contained oocytes apparently without a second meiotic division, which suggests that both races may exist within the population. In MH97-2, one female was viviparous, displaying em- bryogenesis and hatched juveniles inside the body.

North Carolina Differential Host Test. Reproduction of the 14 populations of Meloidogyne on the North Carolina differential hosts was variable but corresponded to expected results for $M$. hapla. The populations reproduced on all NCDHT hosts, except watermelon and cotton (Table 2). Populations MH97-2 and MH97-10 were able to reproduce on watermelon at a level consistent with a maintenance host, and populations MH97-4 and MH97-7 were unable to reproduce on tobacco. Populations MH97-4 and MH97-5 reproduced poorly on peanut. None of the populations was able to reproduce on either wheat or cotton.
NY M. hapla U96303

NC $M$. arenaria $\mathrm{U} 42342$

NY M. hapla

U96303

NC $M$. arenaria $\mathrm{U} 42342$
CCCGTCGCTGCCCGGGACTGAGCCATTTCGAGAAACTTGG

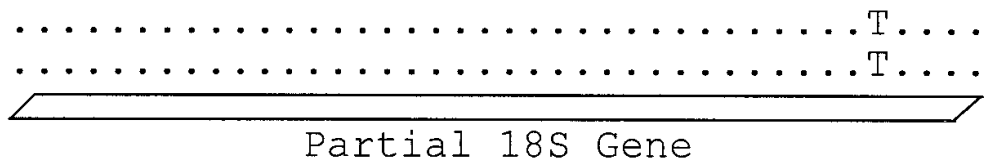

41

80

AGACTGTTGATCTAATTTTTTTAAGTTACTTTGATGGAAA

........

G..C....T..................

G..........................

Partial 18S Gene

81

120

CCAATTTAATCGCAGTGGCTTGAACCGGGCAAAAGTCGTA

NY $M$. hapla
U96303
NC $M$. arenaria
U4 2342

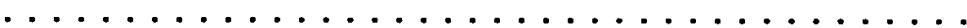

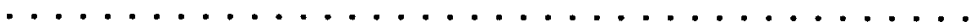

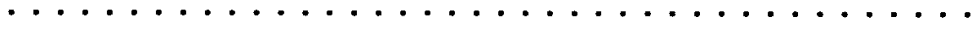

Partial 18S Gene

121

160

NY $M$. hapla

U96303

NC $M$. arenaria

$\mathrm{U} 42342$

ACAAGGTAGCTGTAGGTGAACCTGCTGCTGGATCATTACT

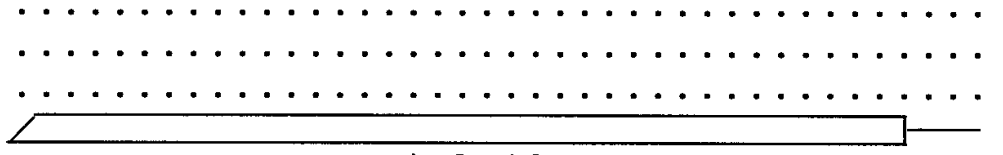

Partial $18 \mathrm{~S}$ Gene
NY M. hapla

U96303

NC $M$. arenaria

$\mathrm{U} 42342$
161

TTTTGTGATGTTCAAATTCGAATAGTCTCAACGT--TTAT

$\ldots-\ldots \ldots \ldots \ldots \ldots \ldots \ldots \ldots \ldots \ldots \ldots \ldots$

.А.................. . . . . .

.................... . АAA.G.

ITS1

(continued on next page)

Fig. 3. Alignment of 18S, ITS1, and 5.8S sequences among Meloidogyne species. NYS M. hapla is a shared sequence among all New York State populations. U96303 is the GenBank Accession number for M. hapla (17). NC M. arenaria is the population obtained from North Carolina used in this study. U42342 is the GenBank Accession number for the corresponding M. arenaria sequence. Sequence identity is indicated by “.” and insertions/deletions by "-". 
ITS region. Sequence similarity was extremely high at $>99.0 \%$. All New York populations were identical in ITS1 sequence and only differed from the published sequence by three thymine base pair insertions (Fig. 3).

\section{DISCUSSION}

Perineal pattern morphology has been the traditional standard for the identification of the most common Meloidogyne species since $1949(4,22)$. The populations in this study were all consistent with perineal patterns of M. hapla and showed little variability. The variability that did exist was primarily a result of differences in size among the nematodes that were dissected. Smaller females frequently had a less-developed pattern than larger, more mature females.

Identification of Meloidogyne species by using the scanning electron microscope to examine nematode morphology has been done only in the past two decades. The technique was described and examined extensively by Eisenback, who showed differences in the lip region between males, females, and juveniles of the four most common Meloidogyne species (8). Populations MH97-12, MH97-15, and MH97-16 were not analyzed using this technique, but all other New York Meloidogyne populations examined displayed lip morphology that is characteristic of $M$. hapla. Although micrographs could not conclusively identify any population as a particular race, the micrographs appeared to be consistent with the lip morphology of race A (meiotically parthenogenic) (5). The head region of all examined nematodes was distinctly set apart from body annules. In males and juveniles, the medial lip shape, the placement of the labial disk, and the shape of lateral lips (when present) were consistent with previous descriptions of $M$. hapla $(6,7)$.

Cytological observations can conclusively determine the race of $M$. hapla populations $(24,25)$. All populations but MH97-8 were identified as race A. Further examination would be required to conclusively determine the race status of MH978. Although this population is diploid, this would not necessarily disqualify it from being race $\mathrm{B}$, as diploid $M$. hapla race $\mathrm{B}$ populations with $2 \mathrm{n}=2 \mathrm{x}=30-32$ have been reported earlier (24). The observed chromosome numbers of MH97-11 ( $\mathrm{n}=$ 17) and MH97-13 $(\mathrm{n}=15)$ are within the range of 14 to 17 that has been described for M. hapla race A populations (24). Variability in chromosome numbers is prevalent among populations of $M$. hapla in New York. Based on the observations in

Fig. 3. (continued from previous page)

NY $M$. hapla
U96303
NC $M$. arenaria
U42342

U 4342
200 CGTTGTGAA-CGGCTGTCGCTGGTGTCTAGGTGTTGCTGA $\ldots \ldots \ldots \ldots \ldots \ldots \ldots \ldots \ldots \ldots \ldots \ldots \ldots \ldots \ldots \ldots \ldots \ldots \ldots$

$\ldots \ldots \ldots$...................

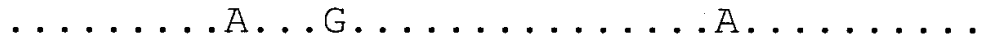

ITS 1

241

280

NY M. hapla

U96303

NC $M$. arenaria $\mathrm{U} 42342$

TTCAGCTGTCAACGTCCGTGGCTGAATATGAGGTGACATG

$\ldots \ldots \ldots \ldots \ldots$

. A..T... . . . . . . . T.... T......

.A.G.T.................. T......

$\operatorname{ITS} 1$

281

NY M. hapla

TTAGGACCTTAATCGGGTTTAAGACTTAATGAGCCTCTTA

$\mathrm{U} 96303$

NC M. arenaria

$\mathrm{U} 42342$

$\ldots \ldots \ldots \ldots \ldots \ldots \ldots \ldots \ldots \ldots \ldots \ldots \ldots \ldots \ldots \ldots \ldots \ldots$

$\ldots \ldots$. . .... . ..............

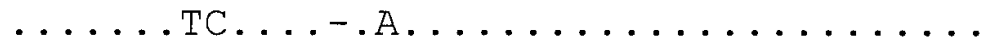

ITS1

321

NY $M$. hapla

AGTGAGGACGCCAGCAATATTTTTTTCAACTATTTTTTTT

U96303

NC $M$. arenaria

$\mathrm{U} 42342$

$\ldots \ldots \ldots \ldots \ldots \ldots \ldots \ldots \ldots \ldots \ldots$

$\ldots . . . . . . . . \mathrm{CC} \ldots \mathrm{TCT} \ldots \mathrm{CA} \ldots \mathrm{....A}$

$\ldots . . . . . . . . . \mathrm{CC} \ldots \mathrm{TCT} \ldots \mathrm{CA} \ldots \mathrm{AA}$

ITS1

361

NY M. hapla

U96303

AAAAAACGA--AAATTTTTATCCTTATCGGTGGATCACTC

NC $M$. arenaria

$\mathrm{U} 42342$

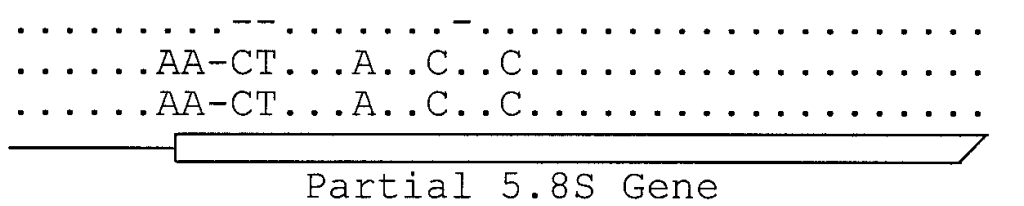


this study, it cannot be excluded with certainty that all populations are purely race A. Some observations indicated that a mixture of race type may occur in MH9711 , but only race A nematodes were conclusively identified.

The NCDHT can be used to aid in identifying species of Meloidogyne present in a particular soil. The usefulness of the test is limited when multiple species are present in a field soil, but this was not an issue in this research because single-female populations were used in the tests. Results from this study using the standard NCDHT hosts and wheat indicate that the New York populations of Meloidogyne collected from vegetable fields comprised only M. hapla. If $M$. chitwoodi had been present in the collected samples, reproduction on wheat would have been observed. Some atypical results were observed with some populations. M. hapla does not typically reproduce on watermelon, but two of the New York populations reproduced on watermelon. Additionally, two New York populations did not reproduce on tobacco. These populations were tested a second time with similar results. Although these results were not expected, it is unlikely that these populations are a species other than M. hapla, based on all of the other data accumulated in this study.

Ribosomal DNA sequences can provide extreme precision and reliability in species diagnosis. Because of low rates of mutation, ribosomal sequences are expected be very consistent among individuals within a species (9). There is a significant degree of sequence similarity among the ribosomal genes of the genus Meloidogyne, and a single primer set is able to reliably amplify the ITS regions of multiple species (17). This allows for the identification of multiple species in mixed populations. While sequence data are definitive, the sizes of restricted ITS fragments can also give an indication of species identity (29).

Powers et al. (17) amplified a region of ribosomal DNA consisting of part of the $18 \mathrm{~S}$ gene, the ITS1, the $5.8 \mathrm{~S}$ gene, the ITS2, and part of the 28S gene of Meloidogyne spp. In the current study, only part of the $18 \mathrm{~S}$ and the $5.8 \mathrm{~S}$ gene and the complete ITS1 were amplified. In identifying differences within and between species, ITS 1 and ITS2 will provide more useful information than the $18 \mathrm{~S}, 5.8 \mathrm{~S}$, or $28 \mathrm{~S}$ genes. Mutations within ITS regions have less impact on organism viability than mutation within functional genes, and therefore mutations will occur at a higher rate in these internal transcribed sequences. Sequence conservation of the $3^{\prime}$ end of the $18 \mathrm{~S}$ gene among Meloidogyne species is too great to reliably facilitate species identification, but the ITS1 region shows considerable sequence variation (17). For these reasons, we chose to focus on ITS1 for Meloidogyne species identification, and all tested popu- lations were identified as M. hapla based on published sequences.

Recently, work by Hugall et al. (13) has demonstrated $25 \%$ sequence divergence among the ITS1, 5.8S, and ITS2 regions of eight Australian populations of M. hapla. In the current study, the $18 \mathrm{~S}$, ITS1, and 5.8S gene sequences from all populations of $M$. hapla within New York were identical ( $0 \%$ sequence divergence). Hugall et al. also observed two distinct $M$. hapla groups based on examined sequences. Within each group, however, sequence diversity was much lower (1.3 to $1.4 \%)$ than among groups. It is possible that two or more groups of M. hapla, based on ITS sequence divergence, exist within the United States. Results from the current study indicate that only one group is present in New York.

Based on the results of this study and the sampling methodology used to collect Meloidogyne populations, M. hapla was the only species of root-knot nematode that was detected in New York vegetable fields. Although there are few vegetable crops that are nonhosts of $M$. hapla, there are nonhost gramineous crops that can be used in a rotation to manage this nematode. This would not be possible if $M$. chitwoodi were present. Specific recommendations for individual fields, however, may be necessary in some cases. In this research, the pathogenicity of the New York populations was variable. It is also possible that the pathogenicity of M. hapla in any particular field may change, requiring continual reevaluation of its effectiveness.

\section{LITERATURE CITED}

1. Abawi, G. S., Widmer, T. L., Ludwig, J. W., and Mitkowski, N. A. 1999. Biology and management of Meloidogyne hapla on carrots, onions and lettuce in New York. J. Nematol. 31:521.

2. Brown, R. H., and Kerry, B. R., eds. 1987. Principles and Practices of Nematode Control in Crops. Academic Press, Orlando, FL. p. 447.

3. Byrd, D. W., Barker, K. R., Ferris, H., Nusbaum, C. J., Griffin, W. E., Small, R. H., and Stone, C. A. 1976. Two semi-automatic elutriators for extracting nematodes and certain fungi from soil. J. Nematol. 8:206-212.

4. Chitwood, B. G. 1949. Root-knot nematodes: Part I. A revision of the genus Meloidogyne Goeldi, 1887. Proc. Helminthological Soc. Washington 16:90-104.

5. Eisenback, J. D. 1993. Morphological comparison of the females, males and secondstage juveniles of cytological races A and B of Meloidogyne hapla Chitwood, 1949. Fundam. Appl. Nematol. 16:259-271.

6. Eisenback, J. D., and Hirschman, H. 1979. Morphological comparison of second-stage juveniles of six populations of Meloidogyne hapla by SEM. J. Nematol. 11:5-16.

7. Eisenback, J. D. and Hirschman, H. 1980. Morphological comparison of Meloidogyne males by scanning electron microscopy. J. Nematol. 12:23-32.

8. Eisenback, J. D., Hirschman, H., Sasser, J. N., and Triantaphyllou, A. C. 1981. A guide to the four most common species of root knot nematodes (Meloidogyne spp.) with a pictorial key. A Cooperative Publication of the Department of Plant Pathology and Genetics, North Caro- lina State University, and the United States Agency for International Development, Raleigh.

9. Elder, J. F., and Turner, B. J. 1995. Concerted evolution of repetitive DNA sequences in eukaryotes. Quart. Rev. Biol. 70:297-320.

10. Ferris, H., Carlson, H. L., Viglierchio, D. R., Westerdahl, B. B., Wu, F. W., Anderson, C. E., Juurma, A., and Kirby, D. W. 1993. Host status of selected crops to Meloidogyne chitwoodi. J. Nematol. 25:849-857.

11. Golden, A. M., O'Bannon, J. H., Santo, G. S., and Finley, A. M. 1980. Description and SEM observations of Meloidogyne chitwoodi $\mathrm{n}$. sp. (Meloidogynidae), a root-knot nematode on potato in the Pacific Northwest. J. Nematol. 12:319-327.

12. Hartman, K. M., and Sasser, J. N. 1985. Identification of Meloidogyne species on the basis of differential host test and perineal pattern morphology. Pages 68-69 in: An Advanced Treatise on Meloidogyne. Vol. II: Methodology. K. R. Barker, C. C. Carter, and J. N. Sasser, eds. NCSU Graphics.

13. Hugall, A., Stanton, J., and Moritz, C. 1999. Reticulate evolution and the origins ribosomal internal transcribed spacer diversity in apomictic Meloidogyne. Mol. Biol. Evol. 16:157-164.

14. Hussey, R. A., and Barker, K. R. 1973. A comparison of methods of collecting inocula of Meloidogyne spp. including a new technique. Plant Dis. Rep. 57:1025-1028.

15. Noliag, L. W., and Becker, J. O. 1994. The challenge of research and extension to define and implement alternatives to methyl bromide. J. Nematol. 26:573-586.

16. Powers, T. O., and Harris, T. S. 1993. A polymerase chain reaction method for identification of five major Meloidogyne species. J. Nematol. 25:1-6.

17. Powers, T. O., Todd, T. C., Burnell, A. M., Murray, P. C. B., Fleming, C. C., Szalanski, A. L., Adams, B. A., and Harris, T. S. 1997. The rDNA internal transcribed spacer region as a taxonomic marker for nematodes. J. Nematol. 29:441-450.

18. Ropel, C. R., and Smith, B. L., eds. 2001. New York Agricultural Statistics, 1999-2000. A Cooperative Publication of the New York State Department of Agriculture and Markets, Division of Statistics, and the United States Department of Agriculture, National Agricultural Statistics Service.

19. Santo, G. S., O’Bannon, J. H., Finley, A. M., and Golden, A. M. 1980. Occurrence and host range of a new root-knot nematode (Meloidogyne chitwoodi) in the Pacific Northwest. Plant Dis. 64:951-952.

20. Sasser, J. N., and Triantaphyllou, A. C. 1977. Identification of Meloidogyne species and races. J. Nematol. 9:283.

21. Slinger, L. A., and Bird, G. W. 1977. Growth and development of carrot in presence of Meloidogyne hapla. J. Nematol. 9:284.

22. Taylor, A. L., Dropkin, V. H., and Martin, G. C. 1955. Perineal patterns of root-knot nematodes. Phytopathology 45:26-34.

23. Taylor, D. P., and Netscher, C. 1974. An improved technique for preparing perineal patterns of Meloidogyne spp. Nematologica 20:268-269.

24. Triantaphylou, A. C. 1985 . Cytogenetics, cytotaxonomy and phylogeny of root-knot nematodes. Pages 112-126 in: An Advanced Treatise on Meloidogyne. Vol. I: Biology and Control. J. N. Sasser and C. C. Carter, eds. A Cooperative Publication of the Department of Plant Pathology and Genetics, North Carolina State University, and the United States Agency for International Development, Raleigh.

25. Van der Beek, J. G., Los, J. A., and Pijnacker, L. P. 1998. Cytology of parthenogenesis of five Meloidogyne species. Fundam. Appl. 
Nematol. 21:393-399.

26. Van Gundy, S. D. 1985. Ecology of Meloidogyne spp. - emphasis on environmental factors affecting survival and pathogenicity. Pages 177-182 in: An Advanced Treatise on Meloidogyne. Vol. I: Biology and Control. J. N. Sasser and C. C. Carter, eds. A Cooperative Publication of the Department of Plant Pathology and Genetics, North Carolina State
University, and the United States Agency for International Development, Raleigh.

27. Walters, S. A., and Barker, K. R. 1994. Current distribution of five major Meloidogyne species in the United States. Plant Dis. 78:772-774.

28. Widmer, T. L., Ludwig, J. W., and Abawi, G. S. 1999. The Northern Root-Knot Nematode on carrot, lettuce and onion in New York.
New York's Food and Life Sciences Bulletin No. 156. Communication Services, New York State Agricultural Experiment Station, Geneva.

29. Zijlstra, C., Uenk, B. J., and Van Silfhout, C. H. 1997. A reliable, precise method to differentiate species of root-knot nematodes in mixtures on the basis of ITS-RFLPs. Fundam. Appl. Nematol. 20(1):59-63. 